\title{
Prenatal exposure to $\beta 2$-adrenergic receptor agonists and risk of autism spectrum disorders
}

\author{
Lisa A. Croen • Susan L. Connors • Marilyn Matevia • \\ Yinge Qian • Craig Newschaffer • \\ Andrew W. Zimmerman
}

Received: 21 January 2011 / Accepted: 9 August 2011 /Published online: 27 August 2011

(C) Springer Science+Business Media, LLC 2011

\begin{abstract}
This study aims to investigate the association between prenatal exposure to terbutaline and other $\beta 2$ adrenergic receptor (B2AR) agonists and autism spectrum disorders (ASDs). The methodology used is a case-control study among children born from 1995 to 1999 at Kaiser Permanente Northern California hospitals. Cases $(n=291)$ were children with an ASD diagnosis; controls $(n=284)$ were children without ASDs, randomly sampled and frequency-matched to cases on sex, birth year, and delivery hospital. Exposure to B2AR agonists during 30 days prior to conception and each trimester of pregnancy was ascertained from prenatal medical records and health plan
\end{abstract}

The findings and conclusions in this report are those of the authors and do not necessarily represent the views of the Centers for Disease Control and Prevention.

L. A. Croen $(\bowtie) \cdot$ M. Matevia $\cdot$ Y. Qian

Division of Research, Kaiser Permanente Northern California,

2000 Broadway,

Oakland, CA 94612, USA

e-mail: lisa.a.croen@kp.org

S. L. Connors $\cdot$ A. W. Zimmerman

Department of Neurology and Developmental Medicine,

Kennedy Krieger Institute,

707 North Broadway,

Baltimore, MD 21205, USA

S. L. Connors

Departments of Medicine and Pediatrics,

Massachusetts General Hospital/LADDERS Clinic,

1 Maguire Road,

Lexington, MA 02142, USA

\section{Newschaffer}

Department of Epidemiology and Biostatistics,

Drexel University School of Public Health,

1505 Race Street-Mail Stop 1033 ,

Philadelphia, PA 19102-1192, USA databases. The frequency of exposure to any B2AR agonist during pregnancy was similar for mothers of children with ASD and mothers of controls (18.9\% vs. $14.8 \%, P=0.19)$. Exposure to B2AR agonists other than terbutaline was not associated with an increased risk for ASDs. However, terbutaline exposure for $>2$ days during the third trimester was associated with more than a fourfold increased risk for ASDs independent of indication although the limited sample size resulted in an imprecise and nonsignificant effect estimate $\left(\mathrm{OR}_{\mathrm{adj}}=4.4 ; 95 \%\right.$ confidence interval, 0.8 24.6). This analysis does not offer evidence linking B2AR exposure in pregnancy with autism risk. However, exposure

A. W. Zimmerman

Center for Autism and Related Disorders,

Kennedy Krieger Institute,

Baltimore, MD, USA

A. W. Zimmerman

Departments of Neurology, Psychiatry and Pediatrics, Johns Hopkins University School of Medicine, Baltimore, MD, USA

A. W. Zimmerman

Department of Epidemiology,

Johns Hopkins Bloomberg School of Public Health,

Baltimore, MD, USA 
to terbutaline during the third trimester for $>2$ days may be associated with an increased risk of autism. Should this result be confirmed in larger samples, it would point to late pregnancy as an etiologic window of interest in autism risk factor research.

Keywords Asthma - Beta 2 adrenergic agonist $\cdot$ B2AR agonists $\cdot$ Autistic $\cdot$ Perinatal risk factors $\cdot$ Terbutaline

\section{Introduction}

Key pathophysiologic changes observed in the brain of autistic individuals provide compelling evidence that autism begins during fetal development (Casanova 2007; Bauman and Kemper 2005; Rodier 2000). While genetic susceptibility undoubtedly underlies autism etiology in many cases (Abrahams and Geschwind 2008), environmental factors likely play a role as well (Cook and Scherer 2008). Evidence has recently emerged linking maternal prenatal exposures such as illnesses, medications, environmental toxins, and psychological stress with autism risk (Connors et al. 2005; Roberts et al. 2007; Beversdorf et al. 2005; Croen et al. 2005).

Terbutaline, a $\beta 2$ adrenergic receptor (B2AR) agonist, has been used off-label for the past 30 years to treat preterm labor. Terbutaline readily crosses the placenta and bloodbrain barrier (Bergman et al. 1984; Hsu et al. 1994; Slotkin et al. 1994) and has been shown in animals to elicit biochemical alterations and structural damage in the immature brain during critical developmental periods (Rhodes et al. 2004). When administered to rats at a neurodevelopmental stage equivalent to the mid-second to early third trimester in humans (Rice and Barone 2000), terbutaline dysregulates function of the enzyme adenylyl cyclase and leads to abnormal generation (excess and deficiency) of the signaling molecule cyclic adenosine monophosphate (cAMP) in different brain regions at different stages of development (Rhodes et al. 2004; Slotkin et al. 2001, 2003; Meyer et al. 2005). Terbutaline exposure during this prenatal window results in changes in the rat central nervous system similar to those found in autism postmortem studies such as cerebellar abnormalities (delays in synaptogenesis and reduction in Purkinje cell number), deficient hippocampal development, and neuroimmune activation (Rhodes et al. 2004; Zerrate et al. 2007; Bauman and Kemper 1985; Vargas et al. 2005; Casanova et al. 2006). In humans, continuous administration of terbutaline for 2 weeks or more between 16 and 36.5 weeks' gestation has been linked to concordance of autism spectrum disorders (ASDs) in dizygotic twins (Connors et al. 2005). The study by Connors et al. ascertained 36 dizygotic twin pairs from autism clinics in which at least one twin had an
ASD diagnosis and found an association (relative risk= 2.28) between terbutaline exposure for more than 2 weeks and concordance for ASDs. The relative risk increased to $4.4(p=0.035)$ in those twin sets who were both male and without a family history of ASDs.

Terbutaline and other B2AR agonists are Food and Drug Administration (FDA) approved for the treatment of asthma, one of the most common conditions that may complicate pregnancy. The use of medications to control asthma during pregnancy is still recommended since uncontrolled asthma is associated with poor birth outcomes (Bracken et al. 2003). Previously, we reported that a diagnosis of asthma in the second trimester was associated with a twofold increased risk of autism in the offspring (Croen et al. 2005). While factors related to the underlying disease process may put pregnant women with asthma at higher risk for having a child on the autism spectrum, the possibility that asthma treatment with B2AR agonists may explain this link requires investigation.

We conducted a case-control study to investigate the potential association between maternal exposure to terbutaline and other B2AR agonists during pregnancy and risk of delivering an infant subsequently diagnosed with an ASD.

\section{Materials and methods}

Our study population was drawn from the Childhood Autism Perinatal Study, a large case-control study examining pre-, peri-, and neonatal risk factors for ASDs among the membership of Kaiser Permanente of Northern California (KPNC; Croen et al. 2005). KPNC is a group model integrated health plan that provides care for over 3.2 million northern California residents. The KPNC membership represents approximately $30 \%$ of the insured population in the region and is demographically similar to the residents of the counties served by KPNC, except that the very poor and very wealthy are underrepresented (Krieger 1992). Cases and controls were identified from the cohort of infants born at a KPNC facility between January 1995 and June 1999 who remained KPNC members for at least 2 years following birth $(n=88,163)$.

Cases were defined as children with at least one diagnosis of an ASD, including autism (International Classification of Diseases 1999; ICD-9-CM code 299.0) and Asperger's Disorder or Pervasive Developmental Disorder Not Otherwise Specified (ICD-9-CM code 299.8) recorded anytime between January 1995 and December 2002 in KPNC outpatient clinical databases $(n=420)$. Children with fragile $\mathrm{X}$ syndrome $(n=2)$, tuberous sclerosis $(n=0)$, or neurofibromatosis $(n=0)$ were excluded. One control per case was randomly selected from the cohort of KPNC births without an ASD 
diagnosis, frequency matched to cases on sex, birth year, and delivery hospital. Since we were interested in examining characteristics of the mother in relation to autism risk in the offspring, we randomly sampled one child for inclusion for each woman who contributed two children to the original study sample (13 case mothers, 5 control mothers). Only children whose mothers were KPNC members with pharmacy benefits from at least 1 month before conception through the end of the pregnancy were included (291 cases, 284 controls). Women with pharmacy benefits during this time period were very likely to have purchased all of their prescription medications at a KPNC pharmacy.

Information on maternal exposure to B2AR agonists was ascertained from the KPNC pharmacy database, which records all dispensed prescriptions at KP pharmacies, and abstracted from prenatal medical records using a standardized form. All inpatient and outpatient prescriptions were identified in the 30 days before conception through the end of the pregnancy with the study child. B2AR agonists included: Advair ${ }^{\circledR}$, albuterol, Combivent ${ }^{\circledR}$, Foradil $^{\circledR}$, Maxair ${ }^{\circledR}$, metaproterenol, Ritodrine ${ }^{\circledR}$, Serevent ${ }^{\mathbb{}}$, terbutaline, Tornalate ${ }^{\circledR}$, and Xopenex ${ }^{\circledR}$ (Table 1). Only two B2AR agonists have been used for tocolysis in the USA, ritodrine and terbutaline. Terbutaline is the generic for Brethine, Bricanyl, and Brethaire, all of which were searched in the pharmacy database along with Ritodrine but only prescriptions for terbutaline were found. Since generic terbutaline is inexpensive and comes in a variety of forms for administration, it was the B2AR agonist in use for tocolysis during the time period of this study. Inhalers, injections, and pills were the only routes of administration included. Topical, ophthalmic, and otic routes were excluded.

Four time periods of exposure were defined: preconception (the 30 days prior to the last menstrual period (LMP)), first trimester (in the 90 days post-LMP), second trimester
(90-180 days post-LMP), and third trimester (180 days post-LMP to date of delivery). To account for possible inaccuracies in LMP date, the preconception period was included as a proxy for very early pregnancy exposure.

The date the prescription was dispensed and the number of days supplied were used to determine exposure status during each time period. Exposure during a given time period was assumed if a prescription was dispensed during the time period or the days supplied overlapped some portion of the time period. Duration of exposure was derived by summing the total number of days during pregnancy for which a B2AR agonist was prescribed. Maternal conditions that were indications for B2AR agonists during pregnancy were identified from inpatient and outpatient databases and abstracted from prenatal records. Clinical indicators included asthma, preterm labor, and conditions that predispose to preterm labor (bicornuate uterus, cervical incompetence, multiple fibroids, hypertension, diabetes, anemia, bacterial vaginosis, pyelonephritis, asymptomatic bacteriuria, chorioamnionitis, urinary tract infection, and sexually transmitted diseases). Information on several maternal and infant characteristics was obtained from health plan and vital statistics databases.

Characteristics of cases and controls were compared using contingency tables for categorical variables and comparisons of means for continuous variables. Unconditional logistic regression analysis was conducted to estimate relative risks of ASD associated with maternal use of B2AR agonists during pregnancy. Separate models were run for all B2AR agonists combined, terbutaline alone, and albuterol alone, the two most frequently used B2AR agonists. For each exposure definition, we examined time period of exposure as well as duration of exposure. We defined exposure duration categories based on the distribution of days of exposure among the control group. For terbutaline, most use was for 1 or 2 days, reflecting acute exposure, or
Table 1 B2AR agonists and mimics included in analyses, listed by indication

$B 2 A R \quad \beta 2$-adrenergic receptor

\begin{tabular}{|c|c|}
\hline B2AR agonists & $\begin{array}{l}\text { Total }(N=575) \\
n(\%)\end{array}$ \\
\hline \multicolumn{2}{|l|}{ Asthma } \\
\hline Salmeterol xinafoate/fluticasone propionate (Advair ${ }^{\circledR}$, Advair HFA ${ }^{\circledR}$ ) & $0(0.00)$ \\
\hline Albuterol, albuterol sulfate $\left(\right.$ Proventil $^{\circledR}$, Ventolin ${ }^{\circledR}$, AccuNeb $\left.^{\circledR}\right)$ & $47(8.17)$ \\
\hline Ipratropium bromide/albuterol sulfate $\left(\right.$ Combivent $\left.{ }^{\mathbb{R}}\right)$ & $0(0.00)$ \\
\hline Formoterol fumarate $\left(\right.$ Foradil $^{\circledR}$, Foradil Aerolizer ${ }^{\circledR}$ ) & $0(0.00)$ \\
\hline Pirbuterol acetate $\left(\right.$ Maxair $\left.^{\circledR}\right)$ & $0(0.00)$ \\
\hline Metaproterenol, metaproterenol sulfate (Alupent ${ }^{\circledR}$, Arm-a-med ${ }^{\circledR}$ (Metapro), Metaprel ${ }^{\circledR}$ ) & $2(0.35)$ \\
\hline Salmeterol xinafoate $\left(\right.$ Serevent $\left.{ }^{\circledR}\right)$ & $2(0.35)$ \\
\hline Levalbuterol HCL (Xopenex ${ }^{\circledR}$ ) & $0(0.00)$ \\
\hline \multicolumn{2}{|l|}{ Pre-term labor } \\
\hline Ritodrine, ritodrine hydrochloride & $0(0.00)$ \\
\hline Terbutaline, terbutaline sulfate (Brethaire ${ }^{\circledR}$, Breathair ${ }^{\mathbb{R}}$, Brethine ${ }^{\mathbb{R}}$ ) & $55(9.57)$ \\
\hline
\end{tabular}


for 10 or more days, reflecting maintenance tocolysis. We also examined exposure to terbutaline for $\geq 2$ weeks, the duration found to be associated with ASD concordance among dizygotic twins in a previous study. For albuterol, duration was dichotomized as $>21$ days vs. $\leq 21$ days, the cut-point representing the median length of exposure among control mothers. Women with no prescriptions or days supplied for any B2AR agonists for the entire period from 30 days before conception through the end of pregnancy were considered unexposed for all analyses. Maternal and infant characteristics associated with maternal exposure to B2AR agonists or case-control status were treated as possible confounders and included as covariates in multivariable models as were the matching variables. All covariates were entered simultaneously into regression models and all statistical tests were two-tailed. Study procedures were approved by the KPNC Northern California Institutional Review Board and the California State Committee for the Protection of Human Subjects.

\section{Results}

Children with autism $(n=291)$ were more likely than controls $(n=284)$ to be a twin or triplet, second born, weighing $<2,500 \mathrm{~g}$ at birth, and have a mother of older age and with higher level of education (Table 2). Among controls, the frequency of exposure to B2AR agonists during pregnancy was higher among women carrying twins compared with singletons ( $45.5 \%$ vs. $13.6 \%, P<0.01$ ), women who delivered preterm compared with term ( $29.4 \%$ vs. $13.9 \%, P=0.08)$, and women who delivered low birth weight compared with normal birth weight children ( $40.0 \%$ vs. $13.9 \%, P=0.02)$.

The prevalence of exposure to any B2AR agonist was similar for the mothers of children with autism compared with mothers of control children for the entire pregnancy period $(18.9 \%$ vs. $14.8 \%, P=0.19)$ as well as for each trimester (Table 3). Albuterol was the most prevalent B2AR agonist among mothers of both cases and controls during the preconception period $(3.1 \%$ vs. $2.1 \%, P=0.46)$, as well as in the first $(4.8 \%$ vs. $3.2 \%, P=0.31)$ and second $(6.2 \%$ vs. $4.9 \%, P=0.51)$ trimesters. Prevalence of exposure to any B2AR agonist was highest in the third trimester for both case and control mothers $(14.1 \%$ vs. $12.0 \%, P=0.45)$. Terbutaline accounted for the majority of thirdtrimester exposures for both cases and controls $(11.0 \%$ vs. $7.8 \%, P=$ 0.18 ) followed by albuterol $(4.1 \%$ vs. $4.2 \%, P=0.95)$. After controlling for covariates (birth order, plurality, maternal age, maternal education, and gestational age) and matching variables (gender, birth year, and delivery hospital), the risk of delivering a child later diagnosed with an ASD was not significantly elevated for women with any B2AR agonist exposures during pregnancy (Table 3 ).
Table 2 Characteristics of the study population, Kaiser Permanente Northern California births, 1995-1999

\begin{tabular}{|c|c|c|c|}
\hline \multirow[t]{2}{*}{ Characteristics } & \multicolumn{2}{|l|}{ No. $(\%)$} & \multirow[t]{2}{*}{$P$ value $\mathrm{e}^{\mathrm{a}}$} \\
\hline & $\begin{array}{l}\text { ASD cases } \\
(n=291)\end{array}$ & $\begin{array}{l}\text { Controls } \\
(n=284)\end{array}$ & \\
\hline Gender (male) & $243(83.51)$ & $230(80.99)$ & 0.43 \\
\hline \multicolumn{4}{|l|}{ Plurality } \\
\hline $\begin{array}{l}\text { Singleton } \\
\text { Twin or triplet }\end{array}$ & $\begin{aligned} 273 & (93.81) \\
18 & (6.19)\end{aligned}$ & $\begin{aligned} 273 & (96.13) \\
11 & (3.87)\end{aligned}$ & 0.21 \\
\hline \multicolumn{4}{|l|}{ Birth order } \\
\hline $\begin{array}{l}\text { First born } \\
\text { Second born }\end{array}$ & $\begin{array}{l}121(41.58) \\
113(38.83)\end{array}$ & $\begin{array}{r}122(42.96) \\
92(32.39)\end{array}$ & \multirow[t]{2}{*}{0.18} \\
\hline Third or later born & $57(19.59)$ & $70(24.65)$ & \\
\hline \multicolumn{4}{|l|}{ Maternal age } \\
\hline $\begin{array}{l}<20 \\
20-24\end{array}$ & $\begin{array}{r}3(1.03) \\
25(8.59)\end{array}$ & $\begin{array}{r}8(2.82) \\
29(10.21)\end{array}$ & \multirow[t]{5}{*}{0.14} \\
\hline $25-29$ & $64(21.99)$ & $79(27.82)$ & \\
\hline $30-34$ & $104(35.74)$ & $99(34.86)$ & \\
\hline $35-39$ & $84(28.87)$ & $60(21.13)$ & \\
\hline$\geq 40$ & $11(3.78)$ & $9(3.17)$ & \\
\hline \multicolumn{4}{|l|}{ Maternal education } \\
\hline $\begin{array}{l}<\mathrm{HS} \\
\mathrm{HS}\end{array}$ & $\begin{array}{l}10(3.44) \\
49(16.84)\end{array}$ & $\begin{array}{l}18(6.34) \\
78(27.46)\end{array}$ & \multirow[t]{4}{*}{$<0.001$} \\
\hline College & $163(56.01)$ & $152(53.52)$ & \\
\hline Post-graduate & $68(23.37)$ & $34(11.97)$ & \\
\hline Unknown & $1(0.34)$ & $2(0.70)$ & \\
\hline \multicolumn{4}{|l|}{ Maternal race/ethnicity } \\
\hline $\begin{array}{l}\text { White, non-Hispanic } \\
\text { White, Hispanic }\end{array}$ & $\begin{array}{r}157(53.95) \\
40(13.75)\end{array}$ & $\begin{array}{r}138(48.59) \\
60(21.13)\end{array}$ & \multirow[t]{4}{*}{0.23} \\
\hline Black & $27(9.28)$ & $24(8.45)$ & \\
\hline Asian & $28(9.62)$ & $24(8.45)$ & \\
\hline Other & $39(13.4)$ & $38(13.38)$ & \\
\hline \multicolumn{4}{|l|}{ Gestational age } \\
\hline $\begin{array}{l}<37 \text { Weeks } \\
\geq 37 \text { Weeks }\end{array}$ & $\begin{array}{c}25(8.59) \\
266(91.41)\end{array}$ & $\begin{array}{c}17(5.99) \\
267(94.01)\end{array}$ & 0.23 \\
\hline \multicolumn{4}{|l|}{ Birthweight } \\
\hline $\begin{array}{l}<2,500 \mathrm{~g} \\
\geq 2,500 \mathrm{~g}\end{array}$ & $\begin{array}{c}24(8.25) \\
267(91.75)\end{array}$ & $\begin{array}{c}10(3.52) \\
274(96.48)\end{array}$ & 0.02 \\
\hline \multicolumn{4}{|l|}{ Parity } \\
\hline $\begin{array}{l}\text { No previous births } \\
\text { One previous birth }\end{array}$ & $\begin{array}{l}126(43.3) \\
114(39.18)\end{array}$ & $\begin{array}{r}118(41.55) \\
91(32.04)\end{array}$ & \multirow[t]{2}{*}{0.03} \\
\hline Two or more previous births & $51(17.53)$ & $75(26.41)$ & \\
\hline \multicolumn{4}{|l|}{ Birth year } \\
\hline $\begin{array}{l}1995 \\
1996\end{array}$ & $\begin{array}{l}85(29.21) \\
65(22.34)\end{array}$ & $\begin{array}{l}75(26.41) \\
72(25.35)\end{array}$ & \multirow[t]{4}{*}{0.81} \\
\hline 1997 & $59(20.27)$ & $57(20.07)$ & \\
\hline 1998 & $59(20.27)$ & $62(21.83)$ & \\
\hline 1999 & $23(7.90)$ & $18(6.34)$ & \\
\hline
\end{tabular}

HS high school

${ }^{\mathrm{a}}$ Chi-square test 
Table 3 Odds ratios (ORs) and 95\% confidence intervals (CIs) for autism spectrum disorders (ASDs) associated with prenatal exposure to B2AR agonists

\begin{tabular}{|c|c|c|c|c|c|c|}
\hline \multirow[t]{2}{*}{ Exposure $^{a}$} & \multicolumn{2}{|l|}{ No. $(\%)$} & \multirow[t]{2}{*}{$P$ value $^{\mathrm{b}}$} & \multirow[t]{2}{*}{ Crude OR $(95 \%$ CI) } & \multirow[t]{2}{*}{ Adjusted OR $(95 \% \mathrm{CI})^{\mathrm{c}}$} & \multirow[t]{2}{*}{ Adjusted OR $(95 \% \mathrm{CI})$} \\
\hline & $\begin{array}{l}\text { ASD cases } \\
(n=291)\end{array}$ & $\begin{array}{l}\text { Controls } \\
(n=284)\end{array}$ & & & & \\
\hline \multicolumn{7}{|l|}{ Any B2AR agonist ${ }^{\mathrm{e}}$} \\
\hline Preconception period & $9(3.09)$ & $6(2.11)$ & 0.46 & $1.6(0.6-4.4)$ & $1.9(0.6-6.1)$ & $2.0(0.6-6.4)$ \\
\hline Pregnancy period & $55(18.90)$ & $42(14.79)$ & 0.19 & $1.4(0.9-2.1)$ & $1.1(0.7-1.9)$ & $1.2(0.7-2.0)$ \\
\hline First Trimester & $15(5.15)$ & $10(3.52)$ & 0.34 & $1.6(0.7-3.5)$ & $1.4(0.6-3.6)$ & $1.6(0.6-4.0)$ \\
\hline Second Trimester & $19(6.53)$ & $15(5.28)$ & 0.53 & $1.3(0.7-2.7)$ & $1.3(0.6-2.8)$ & $1.4(0.6-3.1)$ \\
\hline Third Trimester & $41(14.09)$ & 34 (11.97) & 0.45 & $1.3(0.8-2.0)$ & $1.0(0.6-1.8)$ & $1.1(0.6-1.9)$ \\
\hline \multicolumn{7}{|l|}{ Terbutaline } \\
\hline Preconception period & $0(0.00)$ & $0(0.00)$ & & - & - & - \\
\hline Pregnancy period & $33(11.34)$ & $22(7.75)$ & 0.14 & $1.6(0.9-2.8)$ & $1.2(0.6-2.3)$ & $1.2(0.6-2.4)$ \\
\hline First Trimester & $1(0.34)$ & $0(0.00)$ & 0.32 & - & - & - \\
\hline Second Trimester & $1(0.34)$ & $1(0.35)$ & 0.99 & $1.0(0.1-16.7)$ & $0.8(0.0-29.1)$ & $0.8(0.0-31.8)$ \\
\hline Third Trimester & $32(11.00)$ & $22(7.75)$ & 0.18 & $1.5(0.9-2.7)$ & $1.2(0.6-2.3)$ & $1.2(0.6-2.4)$ \\
\hline \multicolumn{7}{|l|}{ Albuterol } \\
\hline Preconception period & $9(3.09)$ & $6(2.11)$ & 0.46 & $1.6(0.6-4.4)$ & $1.9(0.6-6.1)$ & $2.0(0.6-6.4)$ \\
\hline Pregnancy period & $27(9.28)$ & $20(7.04)$ & 0.33 & $1.4(0.8-2.6)$ & $1.3(0.7-2.6)$ & $1.5(0.7-2.9)$ \\
\hline First Trimester & $14(4.81)$ & $9(3.17)$ & 0.31 & $1.6(0.7-3.8)$ & $1.6(0.6-4.1)$ & $1.7(0.6-4.4)$ \\
\hline Second Trimester & $18(6.19)$ & $14(4.93)$ & 0.51 & $1.3(0.7-2.8)$ & $1.3(0.6-3.0)$ & $1.4(0.6-3.2)$ \\
\hline Third Trimester & $12(4.12)$ & $12(4.23)$ & 0.95 & $1.0(0.5-2.4)$ & $1.0(0.4-2.5)$ & $1.1(0.4-2.7)$ \\
\hline
\end{tabular}

$B 2 A R \quad \beta 2$-adrenergic receptor; $A S D$ autism spectrum disorder; $O R$ odds ratio; $C I$ confidence interval

${ }^{a}$ The reference group had no exposure to any B2AR agonists or mimics from 30 days before conception through delivery

${ }^{\mathrm{b}}$ Chi-square test

${ }^{\mathrm{c}}$ Odds ratios were adjusted for maternal education, maternal age, birth type, gestational age, parity, birth hospital, birth year, and sex

${ }^{\mathrm{d}}$ Odds ratios were adjusted for the variables listed above in addition to asthma and preterm labor indications

${ }^{\mathrm{e}}$ Only five case mothers and seven control mothers had exposure to any B2AR agonist during each trimester of pregnancy

Women with terbutaline exposure for $>2$ days $(N=$ $8(3.2 \%)$ cases vs. $N=2(0.79 \%)$ controls $)$ had a fourfold increased risk of having a child subsequently diagnosed with an ASD $\left(\mathrm{OR}_{\mathrm{adj}}=4.1 ; 95 \%\right.$ confidence interval (CI), 0.7-22.4; Table 4). Among women with $>2$ days of exposure to terbutaline (range, 5-48 days), the mean $( \pm \mathrm{SD})$ duration of exposure was 16.4 (12.1)days for cases and 21 (15.6) days for controls. All women with $>2$ days of exposure to terbutaline were exposed for this duration during the third trimester. In addition to terbutaline exposure at $>2$ days, one case mother had third trimester exposure to albuterol, and two case mothers had second trimester exposure to albuterol. Results were similar for terbutaline exposure of 2 weeks or more (four cases, one control; $\mathrm{OR}=4.3 ; 95 \% \mathrm{CI}, 0.5-38.5$ ). The risk of ASD was not elevated among women with $>21$ days of exposure to albuterol during pregnancy, ( $n=14$ cases, $n=11$ controls; $\mathrm{OR}_{\mathrm{adj}}=1.3 ; 95 \%$ CI, 0.5-3.2; Table 4). Albuterol exposure of $>21$ days duration spanned all three trimesters of pregnancy.
Among women who took any B2AR agonist at some point during pregnancy, $30 \%$ of cases and $36 \%$ of controls had a diagnosis of asthma during pregnancy and $53 \%$ of cases and $43 \%$ of controls had a diagnosis of preterm labor. Among women who were exposed to terbutaline during pregnancy, 0 case mothers and $1(4.5 \%)$ control mothers had a diagnosis of asthma only, $28(84.5 \%)$ of case mothers and $18(81.8 \%)$ of control mothers had a diagnosis of preterm labor only, and $3(9.1 \%)$ case mothers and no control mothers had both asthma and preterm labor diagnoses.

In order to explore the effect of terbutaline exposure on autism risk independent of the effect of the indicating condition, we first controlled for the indicating condition via adjustment. Logistic regression models were fit including both the treatment variable and indicating illness as predictor variables. Controlling for indication, the risk of ASD associated with terbutaline exposure for $>2$ days $\left(\mathrm{OR}_{\mathrm{adj}}=\right.$ 4.4; 95\% CI, 0.8-24.6) or $\geq 2$ weeks $\left(\mathrm{OR}_{\mathrm{adj}}=4.7 ; 95 \% \mathrm{CI}\right.$, 0.4-53.3) during the third trimester of pregnancy remained 
Table 4 Adjusted ORs and 95\% CIs for ASDs associated with duration of exposure to B2AR agonists during pregnancy

\begin{tabular}{|c|c|c|c|c|}
\hline \multirow[t]{2}{*}{ Exposure $^{a}$} & \multicolumn{2}{|l|}{ No. $(\%)$} & \multirow[t]{2}{*}{ Adjusted OR $(95 \% \mathrm{CI})^{\mathrm{b}}$} & \multirow[t]{2}{*}{ Adjusted OR $(95 \% \mathrm{CI})^{\mathrm{c}}$} \\
\hline & ASD case $(n=291)$ & Control $(n=284)$ & & \\
\hline \multicolumn{5}{|l|}{ Terbutaline } \\
\hline$>2$ Days $^{\mathrm{d}}$ & $8(2.75)$ & $2(0.704)$ & $4.1(0.8-22.4)$ & $4.4(0.8-24.6)$ \\
\hline 1-2 Days & $24(8.25)$ & $19(6.69)$ & $1.0(0.5-2.0)$ & $1.0(0.5-2.0)$ \\
\hline \multicolumn{5}{|l|}{ Albuterol } \\
\hline$>21$ Days $^{\mathrm{e}}$ & $14(4.81)$ & $11(3.87)$ & $1.3(0.5-3.1)$ & $1.4(0.6-3.5)$ \\
\hline$\leq 21$ Days & $13(4.47)$ & $9(3.17)$ & $1.2(0.5-3.1)$ & $1.3(0.5-3.4)$ \\
\hline
\end{tabular}

$B 2 A R \quad \beta 2$-adrenergic receptor; $O R$ odds ratio; $C I$ confidence interval

${ }^{\mathrm{a}}$ The reference group had no exposure to any B2AR agonists from 30 days before conception through delivery; cut-points for duration based on distribution of length of exposure among control mothers

${ }^{\mathrm{b}}$ Odds ratios were adjusted for maternal education, maternal age, birth type, gestational age, parity, birth hospital, birth year, and sex

${ }^{c}$ Odds ratios were adjusted for variables listed above in addition to asthma and preterm labor indications

${ }^{\mathrm{d}}$ All women with $>2$ days of exposure were exposed for this duration in the third trimester

${ }^{\mathrm{e}}>21$ Days of exposure occurred across multiple trimesters

elevated. We also estimated the effect of terbutaline exposure in a subsample restricted to those women with an indicating medical condition (asthma or preterm labor). In this subsample, terbutaline exposure for $>2$ days $\left(\mathrm{OR}_{\mathrm{adj}}=5.6\right.$, $95 \%$ CI $0.9-34.1)$ or $\geq 2$ weeks (OR $=4.4,95 \%$ CI $0.5-39.8$ ) in the third trimester remained associated with autism risk. This estimate is not confounded by the effect of an indicating condition, as all women included had an indication, but it is possible that some of the effect is due to interaction between indication and exposure.

All results were similar for the subset of children who were singletons (data not shown). There were too few twins to examine as a separate group. We repeated all analyses in an expanded sample of women who had pharmacy benefits in the third trimester, whether or not they had pharmacy benefits throughout pregnancy ( 360 cases, 342 controls). In this larger sample, the risk of ASD associated with terbutaline exposure longer than 2 days was significantly elevated after adjusting for indication and other covariates (11 cases, 2 controls; $\mathrm{OR}_{\mathrm{adj}}=5.8 ; 95 \% \mathrm{CI}, 1.2-28.4$ ). Results were similar for terbutaline exposure for $\geq 2$ weeks (six cases, one control; OR=5.8; 95\% CI, 0.7-48.6).

\section{Discussion}

It is unlikely that a single exposure or insult is responsible for all cases of biologically complex and clinically heterogeneous neurodevelopmental disorders such as those included in the autism spectrum. Yet, it is possible that downstream cellular signaling abnormalities, such as dysregulated cAMP generation, could act as a common pathway in the development of these disorders in some individuals (Connors 2008; Witter et al. 2009). With this in mind, we investigated terbutaline and other B2AR agonists since animal studies have shown that these drugs produced functional changes in developing tissues and behaviors comparable to those noted in autism.

In this case-control study, we did not find evidence of an association between B2AR agonist exposure and autism risk when considering either any B2AR exposure or albuterol exposure specifically. We did find a suggestion of an association between prolonged maternal exposure to terbutaline for more than 2 days in the third trimester and ASD risk, although the effect estimate was imprecise due to the small sample size. We did not see an association for second trimester exposure which is where most of the animal studies have focused. This may have been due to the fact that only two women had second trimester exposures to terbutaline in our population. One previous report linked prolonged terbutaline exposure during the second and third trimesters to ASD concordance among 36 sets of dizygotic autism twin pairs (Connors et al. 2005). Because twin pregnancies are at high risk for exposure to tocolytics, a dizygotic twin series provided an opportunity to explore a potential association in a relatively small sample size. However, twin pregnancies differ in many ways from singleton pregnancies and the twin sample previously studied was a clinical case series and not derived from a population-based frame. In this investigation, we were able to focus on the far larger group of singleton cases drawn from a large KPNC-enrolled sampling frame. Further review of our results also indicates that maternal treatment with B2AR agonists during pregnancy does not explain our previous observation of increased ASD risk among asthmatic mothers (Croen et al. 2005) 
Although this study employs a larger study population than previous reports investigating B2AR exposure and autism risk in human populations, our analysis still generated statistically imprecise effect estimates. For measures of any exposure to all B2AR agonists, albuterol or terbutaline, odds ratios point estimates were also small in magnitude (below 2.0). For long-duration terbutaline exposure in the third trimester where a large odds ratio point estimate was seen, the proportion exposed was very small $(<1 \%$ in the controls) and the resulting confidence limits were quite wide. Larger study populations will be needed to adequately investigate long-duration exposure.

This analysis had the advantage of relying on prospectively collected information on prescribed medications which allowed for examination of risk for specific periods during pregnancy and duration of exposure. However, these records document dispensed prescriptions and therefore exposure could have been misclassified if women did not take the medications as indicated. Although we controlled for many potential confounding factors, including indicators for preterm labor, the possibility that longer duration treatment with terbutaline may in fact represent a marker for an underlying pathogenic process (e.g., maternal stress or inflammation) rather than a risk factor for ASD cannot be completely ruled out.

ASD case status was determined by diagnoses recorded in medical records. A subset of 50 cases was also evaluated with the Autism Diagnostic InterviewRevised (Lord et al. 1994) and the Autism Diagnostic Observation Schedule-Generic (Lord et al. 2000) in a previously published validation study (Croen et al. 2008). Of these 50 cases, $94 \%$ met criteria for ASD on both instruments and $100 \%$ met criteria on at least one. In addition, it was reported that at least $90 \%$ of children with an ASD diagnosis recorded in the KPNC electronic databases had documentation consistent with a diagnosis of autism based on Diagnostic and Statistical Manual of Mental Disorders (fourth edition) criteria (Croen et al. 2008). In the analysis reported here, we were unable to stratify cases into phenotypic subgroups based on severity of ASD or other characteristics as the data in the medical records were not sufficient to accurately and completely make these distinctions. Evaluation of genotypic subgroups may also be important in fully understanding the effects of maternal exposure to B2AR agonists. Of note, variants at two polymorphic sites on the B2AR gene whose function is believed to be related to increased responsiveness of the receptor to ligand have been associated preliminarily with autism risk (Connors et al. 2005; Cheslack-Postava et al. 2007). In our study, genetic data were not available and there was no way to investigate whether B2AR exposure effects might have been stronger in subgroups defined by genotype.
The possibility of a large-magnitude association between terbutaline exposure of more than 2 days in duration during the third trimester and autism risk does have public health implications. One or 2 days of treatment is consistent with brief exposure as defined in a "Dear Colleague" letter sent by the FDA in 1997 alerting practitioners, home healthcare agencies, insurance carriers, and others that "the demonstrated value of tocolytics in general is limited to an initial, brief period of treatment, probably no more than 48-72 h" (US Food and Drug Administration (FDA) and Nightingale 1997). More than 2 days of continued administration is considered "maintenance" therapy. As indicated above, more than half of the women in this category had exposures for 2 or more weeks' duration. There already is a documented lack of evidence for safety and efficacy of maintenance tocolysis (Larsen et al. 1986; The Canadian Preterm Labor Investigators Group 1992; Higby et al. 1993; Hudgens and Conradi 1993). Terbutaline's ability to arrest uterine contractions wanes within $48 \mathrm{~h}$ because the beta- 2 receptors in the myometrium downregulate and desensitize in response to continuous stimulation (Frambach et al. 2005). In addition, other factors that govern uterine contractions are likely to provide a continuing stimulus that is not overcome by B2AR agonists. In contrast to the mature receptor forms found in the uterus, B2ARs in the immature brain sensitize in response to sustained stimulation by terbutaline, which leads to persistent activation and abnormal downstream intracellular signaling in animals (Slotkin and Seidler 2006).

In 2003, the American College of Obstetrics and Gynecology published a practice bulletin for the management of preterm labor, stating that "neither maintenance treatment with tocolytic drugs nor repeated acute tocolysis improve perinatal outcome; neither should be undertaken as a general practice" (ACOG Practice Bulletin 2003). Should prolonged exposure to terbutaline for more than 2 days during pregnancy be associated with increased risk of ASD this would be another important factor dissuading the use of maintenance treatment with tocolytic drugs for the management of preterm labor. Terbutaline is no longer used to treat preterm labor at KPNC. However, surveys of obstetric providers indicate that terbutaline is still being used as a maintenance tocolytic in other medical communities (Fox et al. 2008; Morgan et al. 2008).

\section{Conclusion}

Prenatal exposure to any B2AR occurred at a similar rate among children with autism and control children. Asthma treatment with $\mathrm{B} 2 \mathrm{AR}$ agonists during pregnancy does not explain our previous observation of increased ASD risk among asthmatic mothers. There is a suggestion that 
maternal exposure to terbutaline for greater than 2 days during the third trimester of pregnancy could be associated with elevated autism risk-however, larger studies are needed. Should this association be confirmed, it would provide further contraindication to maintenance tocolysis with B2ARs and also raise interesting questions about late pregnancy mechanisms and exposures to be considered in autism risk factor research.

Acknowledgments We thank Dorothy E. Crowell for bringing the issue of terbutaline exposure to our attention, Theodore A. Slotkin, $\mathrm{PhD}$, for his extensive work on the B2AR and valuable advice; James P. Reichmann, MBA, American Home Patient, Brentwood, TN; and Kaht Dorward, MD, Kaiser Permanente Northern California, for helpful historical insights concerning the use of terbutaline for tocolysis. We also thank Roxana Odouli, MSPH, for her help with project coordination; Darmell Brown and Martha Estrada for performing all medical record review and abstraction; and Cathleen Yoshida, MS, for preparing and managing all study data files. This study was funded by grants from the Centers for Disease Control and Prevention, U10/CCU920392, Kaiser Foundation Research Institute and Autism Speaks.

\section{Conflict of interest None.}

Disclosure Dr. Zimmerman has served as an expert witness in litigation concerning terbutaline and autism.

\section{References}

Abrahams BS, Geschwind DH. Advances in autism genetics: on the threshold of a new neurobiology. Nat Rev Genet. 2008;9 (5):341-55.

ACOG Practice Bulletin. Management of preterm labor, number 43. May 2003. Int J Gynaecol Obstet. 2003;82(1):127-35.

Bauman M, Kemper TL. Histoanatomic observations of the brain in early infantile autism. Neurology. 1985;35(6):866-74.

Bauman ML, Kemper TL. Neuroanatomic observations of the brain in autism: a review and future directions. Int $\mathrm{J}$ Dev Neurosci. 2005;23(2-3):183-7.

Bergman B, Bokstrom H, Borga O, Enk L, Hedner T, Wangberg B. Transfer of terbutaline across the human placenta in late pregnancy. Eur J Respir Dis Suppl. 1984;134:81-6.

Beversdorf DQ, Manning SE, Hillier A, Anderson SL, Nordgren RE, Walters SE, et al. Timing of prenatal stressors and autism. J Autism Dev Disord. 2005;35(4):471-8.

Bracken MB, Triche EW, Belanger K, Saftlas A, Beckett WS, Leaderer BP. Asthma symptoms, severity, and drug therapy: a prospective study of effects on 2205 pregnancies. Obstet Gynecol. 2003;102(4):739-52.

Casanova MF. The neuropathology of autism. Brain Pathol. 2007;17 (4):422-33.

Casanova MF, van Kooten IA, Switala AE, Van Engeland H, Heinsen $\mathrm{H}$, Steinbusch HW, et al. Minicolumnar abnormalities in autism. Acta Neuropathol (Berl). 2006;112(3):287-303.

Cheslack-Postava K, Fallin MD, Avramopoulos D, Connors SL, Zimmerman AW, Eberhart CG, et al. beta2-Adrenergic receptor gene variants and risk for autism in the AGRE cohort. Mol Psychiatry. 2007;12(3):283-91.
Connors SL. Prenatal beta 2 adrenergic receptor signaling and autism: dysmaturation and retained fetal function. In: Zimmerman AW, editor. Autism: current theories and evidence. Totowa: Humana; 2008. p. 147-82.

Connors SL, Crowell DE, Eberhart CG, Copeland J, Newschaffer CJ, Spence SJ, et al. Beta2-adrenergic receptor activation and genetic polymorphisms in autism: data from dizygotic twins. J Child Neurol. 2005;20(11):876-84.

Cook Jr EH, Scherer SW. Copy-number variations associated with neuropsychiatric conditions. Nature. 2008;455(7215):919-23.

Croen LA, Grether JK, Yoshida CK, Odouli R, Van de Water J. Maternal autoimmune diseases, asthma and allergies, and childhood autism spectrum disorders: a case-control study. Arch Pediatr Adolesc Med. 2005;159(2):151-7.

Croen LA, Matevia M, Yoshida CK, Grether JK. Maternal Rh D status, anti-D immune globulin exposure during pregnancy, and risk of autism spectrum disorders. Am J Obstet Gynecol. 2008;199(3):234-6.

Fox NS, Gelber SE, Kalish RB, Chasen ST. Contemporary practice patterns and beliefs regarding tocolysis among US maternal-fetal medicine specialists. Obstet Gynecol. 2008;112(1):42.

Frambach T, Muller T, Freund S, Engelhardt S, Sutterlin M, Lohse MJ, et al. Self-limitation of intravenous tocolysis with beta 2adrenergic agonists is mediated through receptor $G$ protein uncoupling. J Clin Endocrinol Metab. 2005;90(5):2882.

Higby K, Xenakis EMJ, Pauerstein CJ. Do tocolytic agents stop preterm labor? A critical and comprehensive review of efficacy and safety. Am J Obstet Gynecol. 1993;168(4):1247.

Hsu CH, Robinson CP, Basmadjian GP. Tissue distribution of 3Hterbutaline in rabbits. Life Sci. 1994;54(20):1465-9.

Hudgens DR, Conradi SE. Sudden death associated with terbutaline sulfate administration. Am J Obstet Gynecol. 1993;169 (1):120-1.

International Classification of Diseases. Clinical modification (ICD-9-CM), 9th revision. Los Angeles: Practice Management Information Corporation; 1999.

Krieger N. Overcoming the absence of socioeconomic data in medical records: validation and application of a census-based methodology. Am J Public Health. 1992;82(5):703-10.

Larsen JF, Eldon K, Lange AP, Leegaard M, Osler M, Olsen JS, et al. Ritodrine in the treatment of preterm labor: second Danish Multicenter Study. Obstet Gynecol. 1986;67(5):607-13.

Lord C, Rutter M, Le Couteur A. Autism diagnostic interviewrevised: a revised version of a diagnostic interview for caregivers of individuals with possible pervasive developmental disorders. J Autism Dev Disord. 1994;24(5):659-85.

Lord C, Risi S, Lambrecht L, Cook Jr EH, Leventhal BL, DiLavore PC, et al. The autism diagnostic observation schedule-generic: a standard measure of social and communication deficits associated with the spectrum of autism. J Aut Dev Dis. 2000;30(3):205-23.

Meyer A, Seidler FJ, Aldridge JE, Slotkin TA. Developmental exposure to terbutaline alters cell signaling in mature rat brain regions and augments the effects of subsequent neonatal exposure to the organophosphorus insecticide chlorpyrifos. Toxicol Appl Pharmacol. 2005;203(2):154-66.

Morgan MA, Goldenberg RL, Schulkin J. Obstetrician-gynecologists' screening and management of preterm birth. Obstet Gynecol. 2008;112(1):35-41.

US Food and Drug Administration (FDA) and Nightingale SL. Dear colleague letter. November 13, 1997.

Rhodes MC, Seidler FJ, Abdel-Rahman A, Tate CA, Nyska A, Rincavage HL, et al. Terbutaline is a developmental neurotoxicant: effects on neuroproteins and morphology in cerebellum, hippocampus, and somatosensory cortex. J Pharmacol Exp Ther. 2004;308(2):529-37. 
Rice D, Barone Jr S. Critical periods of vulnerability for the developing nervous system: evidence from humans and animal models. Environ Health Perspect. 2000;108 Suppl 3:511-33.

Roberts EM, English PB, Grether JK, Windham GC, Somberg L, Wolff C. Maternal residence near agricultural pesticide applications and autism spectrum disorders among children in the California Central Valley. Environ Health Perspect. 2007;115(10):1482-9.

Rodier PM. The early origins of autism. Sci Am. 2000;282(2):56-63.

Slotkin TA, Seidler FJ. Anomalous regulation of adrenoceptor signaling in brain regions of the newborn rat. Brain Res. 2006;1077(1):54-8.

Slotkin TA, Lau C, McCook EC, Lappi SE, Seidler FJ. Glucocorticoids enhance intracellular signaling via adenylate cyclase at three distinct loci in the fetus: a mechanism for heterologous teratogenic sensitization? Toxicol Appl Pharmacol. 1994;127 (1):64-75.

Slotkin TA, Tate CA, Cousins MM, Seidler FJ. Beta-adrenoceptor signaling in the developing brain: sensitization or desensiti- zation in response to terbutaline. Brain Res Dev Brain Res. 2001;131(1-2):113-25.

Slotkin TA, Auman JT, Seidler FJ. Ontogenesis of beta-adrenoceptor signaling: implications for perinatal physiology and for fetal effects of tocolytic drugs. J Pharmacol Exp Ther. 2003;306 (1): $1-7$.

The Canadian Preterm Labor Investigators Group. Treatment of preterm labor with the beta-adrenergic agonist ritodrine. N Engl J Med. 1992;327(5):308-12.

Vargas DL, Nascimbene C, Krishnan C, Zimmerman AW, Pardo CA. Neuroglial activation and neuroinflammation in the brain of patients with autism. Ann Neurol. 2005;57(1):67-81.

Witter FR, Zimmerman AW, Reichmann JP, Connors SL. In utero beta 2 adrenergic agonist exposure and adverse neurophysiologic and behavioral outcomes. Am J Obstet Gynecol. 2009;201(6):553-9.

Zerrate MC, Pletnikov M, Connors SL, Vargas DL, Seidler FJ, Zimmerman AW, et al. Neuroinflammation and behavioral abnormalities after neonatal terbutaline treatment in rats: implications for autism. J Pharmacol Exp Ther. 2007;322(1):16-22. 